\title{
EMPREENDEDORISMO SUSTENTÁVEL ENQUANTO EMPREENDEDORISMO INSTITUCIONAL: ESTRATÉGIAS DE MOBILIZAÇÃO E DE LEGITIMAÇÃO PARA A MUDANÇA
}

\section{SUSTAINABLE ENTREPRENEURSHIP AS INSTITUTIONAL ENTREPRENEURSHIP: RESOURCE MOBILIZATION AND LEGITIMATION STRATEGIES FOR CHANGE}

\author{
Patrícia Ayumi H.V. de Carvalho \\ Doutoranda de Administração de Empresas na Pontifícia Universidade Católica do Rio de Janeiro- PUC-Rio \\ Rio de Janeiro, RJ, Brasil \\ Email: ayumihodge@gmail.com \\ Marcos Cohen \\ Doutor e Professor Assistente no Departamento de Administração de Empresas na Pontifícia Universidade Católica do Rio de Janeiro- \\ PUC-Rio \\ Rio de Janeiro, RJ, Brasil \\ Email: mcohen@iag.puc-rio.br
}

\section{RESUMO}

Tendo como escopo a ação de empreendedores sustentáveis e unindo os mecanismos típicos da ação empreendedora (causation, effectuation e bricolagem) às estratégias de empreendedores institucionais, o estudo teve como objetivo elucidar a forma com que empreendedores sustentáveis mobilizam recursos ao mesmo tempo em que tentam se legitimar e atrair stakeholders para o seu negócio. Utilizou-se a metodologia de estudo de casos múltiplos, analisando-se três casos de empreendedores sustentáveis no Brasil. A principal contribuição da adoção da teoria institucional à pesquisa sobre empreendedorismo sustentável foi mostrar que a utilização dos mecanismos da ação empreendedora varia conforme o contexto, priorizando-se a lógica de causation quando o objetivo é de busca por legitimidade e convencimento de stakeholders, numa tentativa de mudança institucional. Também se constatou que os argumentos da teorização também apresentam variações ao longo do tempo, conforme a experimentação e o aprendizado iterativo dos empreendedores, seguindo uma lógica de effectuation, à medida que novos desafios e oportunidades surjam para o empreendedor.

Palavras-chave: Empreendedorismo Sustentável. Empreendedorismo Institucional. Bricolagem.

\section{ABSTRACT}

This study focuses on the action of sustainable entrepreneurs, here defined as those who try to solve environmental and social problems, besides generating wealth. We combine the typical mechanisms of entrepreneurial action (causation, effectuation and bricolage) to the strategies of institutional entrepreneurs aiming to unveil the way in which sustainable entrepreneurs mobilize resources while trying to legitimize and atract stakeholders to their business. We used the methodology of multiple case studies analyzing three cases of sustainable entrepreneurs in Brazil. The main contribution of the adoption of institutional theory to sustainable entrepreneurship research is to show that the use of the mechanisms of entrepreneurial action varies according to the context, prioritizing the logic of causation when the objective is to search for legitimacy and convincing stakeholders, in an attempt to promote institutional change. It was also found that the arguments of theorization may vary over time, depending on the experimentation and the iterative learning of entrepreneurs, following a logic of effectuation, as new challenges and opportunities emerge and require appropriation of theorizing arguments by them.

Keywords: Sustainable entrepreneurship. institutional entrepreneurship. effectuation. causation. bricolage.

Data de aprovação: 16 de julho de 2019. 


\section{INTRODUÇÃO}

Em um recente artigo publicado no Academy of Management Journal, George et al. (2016), convidam pesquisadores da área a entrar no debate sobre grandes desafios globais (grand challenges), tais como mudanças climáticas e gestão de recursos naturais, atualmente majoritariamente restrito às áreas de políticas públicas, economia, ciências naturais e engenharia. Já existe uma tendência ao consenso na comunidade científica de que as causas da degradação ambiental residem na forma com que a sociedade consome e se utiliza dos recursos naturais, exigindo uma completa transformação dos atuais sistemas de produção e consumo para que se atinja o desenvolvimento sustentável (Cook et al., 2016). É neste contexto que o empreendedorismo desponta como peça-chave para essa transformação. O empreendedor sustentável - o empreendedor que tenta resolver problemas ambientais e sociais, além de gerar riqueza econômica - pode criar inovações que permitam lucros acima da média, ao mesmo tempo em que resolvam e/ou mitiguem os efeitos da ação do homem sobre o meio-ambiente (Brunelli \& Cohen, 2012; Dean \& McMullen, 2007).

Para a pesquisa em empreendedorismo, a forma com que empreendedores identificam, avaliam e combinam recursos para explorar as oportunidades é diferente da de executivos de empresas, devido à limitação de recursos (Parker, 2011). O empreendedor utiliza uma lógica de effectuation (Sarasvathy, 2001) ou bricolagem (Baker \& Nelson, 2005), em que os recursos em mãos determinam a tomada de decisão sobre a identificação ou criação (Welter, Mauer \& Wuebker, 2016) e exploração de uma determinada oportunidade (Fisher, 2012). Um executivo de empresa, por sua vez, adquire recursos a posteriori, sendo primeiramente realizadas análises de gaps de mercado e definição de objetivos de negócios, seguindo uma lógica de causation (Fisher, 2012; Sarasvathy, 2001).

Os empreendedores sustentáveis, em particular, enfrentam barreiras para sua atuação na medida em que enfrentam alta incerteza quanto ao mercado e ao retorno do investimento (Aldrich \& Fiol, 1994; Karakaya, Hidalgo e Nuur, 2014). Adicionalmente, seus produtos/serviços exigem mudanças nas chamadas instituições, isto é, nos sistemas de regras e normas construídos socialmente e que produzem comportamentos rotineiros e entranhados de tal forma que são custosos de se abrir mão (Aldrich \& Fiol, 1994; Scott, 2013). Essa tentativa de mudança institucional faz com que os empreendedores sustentáveis atuem como empreendedores institucionais, ou seja, como agentes de mudanças institucionais divergentes (DiMaggio, 1988).

O presente trabalho parte da ótica institucional ao categorizar os empreendedores sustentáveis como institucionais e combina essa ótica com a pesquisa em empreendedorismo ao avaliar conjuntamente as estratégias de legitimação e convencimento de stakeholders com os mecanismos da ação empreendedora de effectuation, causation e bricolagem. As perguntas que guiaram a pesquisa foram: 1) Como empreendedores sustentáveis identificam, avaliam e decidem explorar oportunidades de negócio? 2) Como eles mobilizam recursos através das lógicas de causation, effectuation ou bricolagem? e 3) Como eles tentam se legitimar e convencer stakeholders a adotarem seus produtos/serviços?

Ao combinar a perspectiva da teoria institucional à pesquisa em empreendedorismo, unindo as estratégias de legitimação e convencimento dos stakeholders aos mecanismos da ação empreendedora em empreendimentos sustentáveis, esta pesquisa preenche uma lacuna de pesquisa em ambas as áreas (Pacheco et al., 2010; Phillips \& Tracey, 2007; Su, Zhai e Karlsson, 2016; Tolbert, David e Sine, 2011), além 
de contribuir para a pesquisa em empreendedorismo sustentável e para os grand challenges (George et al., 2016).

\section{REFERENCIAL TEÓRICO}

\section{Empreendedorismo e os mecanismos da ação empreendedora}

A relação entre o indivíduo e a oportunidade é o principal tema da pesquisa em empreendedorismo (Davidsson, 2015; Shane \& Venkarataram, 2000). Para Alvarez \& Busenitz (2001), as oportunidades de se oferecer valor à sociedade por meio de um novo produto/serviço surgem pelo fato de alguns indivíduos empreendedores possuírem diferentes crenças sobre o valor relativo dos recursos no processo de conversão de insumos para produtos/serviços. Caso esses indivíduos acertem em suas crenças na oportunidade, seu prêmio viria na forma de ganhos econômicos.

Segundo Davidsson (2015), para que a promessa de benefícios econômicos de uma oportunidade se concretize, é necessário que um ator social a identifique e tome a ação necessária para aproveitá-la. Por conseguinte, a própria figura do empreendedor e suas características cognitivas e sociais são recursos valiosos para que ele possa coletar, nas suas relações sociais, pedaços de informações os quais possam levar a novos empreendimentos (Shane, Locke e Collins, 2003). Nesse contexto, Alvarez \& Busenitz (2001) ressaltam a importância da rede de contatos para expor o empreendedor a uma ampla gama de diferentes tipos de pessoas e situações que possa the prover mais insights sobre oportunidades de negócios. Essa mesma rede de contatos pode suprir a restrição de recursos que a maior parte das start-ups enfrenta.

No processo de identificação das oportunidades e tomada de decisão quanto a sua exploração, o modelo tradicional de empreendedorismo segue o racional econômico em que os empreendedores começam com a busca por áreas em que a demanda por um determinado bem ou serviço seja maior que a oferta, para posteriormente avaliarem se aquela oportunidade vale a pena ser explorada ou não. A partir daí, o empreendedor busca recursos que viabilizem a exploração da oportunidade, criando uma empresa e desenvolvendo os produtos e serviços para serem comercializados. Este modelo foi denominado de causation (Sarasvathy, 2001).

Modelos alternativos sobre o processo de empreendedorismo incluem a lógica de effectuation (Sarasvathy, 2001) e a bricolagem (Baker \& Nelson, 2005). No primeiro, os indivíduos se concentram nos recursos que possuem para decidirem aonde querem chegar, relegando os esforços com planejamento e predição de futuro a um segundo plano. Os recursos são tidos como dados e o enfoque passa a ser na escolha entre possíveis resultados que podem ser obtidos a partir dos meios/recursos em mãos. Os empreendedores partem de três tipos de recursos iniciais para realizarem suas aspirações: eles sabem quem são, o que sabem e quem conhecem. Dessa forma, a lógica de effectuation gira em torno do ator social, ao passo que a da causation é construída em torno dos efeitos da ação empreendedora (Fisher, 2012; Sarasvathy, 2001). Muito embora a lógica de effectuation tenha sido criada por Sarasvathy (2001) a partir de experimentos com empreendedores experientes, pesquisas mais recentes vêm aplicando esta abordagem para outros tipos de empreendedores (Reymen et al., 2015; Welter, Mauer \& Wuebker, 2016). 
O mecanismo de bricolagem, por sua vez, também parte dos recursos que o empreendedor já possui (Fisher, 2012). No entanto, o enfoque desse mecanismo é no processo criativo de empreendedores que conseguem produzir inovações com poucos recursos em mãos, em ambientes de penúria que apresentam novos desafios e os mesmos recursos (Baker \& Nelson, 2005). A bricolagem empreendedora pode ser utilizada nos seguintes domínios: 1) insumos físicos, quando são utilizados materiais esquecidos, descartados ou usados, fazendo com que tenham um novo valor de uso; 2) insumos de trabalho, quando clientes, fornecedores e seguidores participam de projetos dando como recurso seu próprio trabalho; 3 ) insumos de habilidades, quando há utilização de habilidades de amadores e de autodidatas que, de outra forma, não seriam utilizados; 4) clientes/mercado, quando são providos serviços ou bens que de outra forma seriam indisponíveis, e 5) ambiente institucional e regulatório, quando indivíduos empreendedores se recusam a aceitar as limitações desses ambientes (Baker \& Nelson, 2005; Fisher, 2012).

Assim, é possível concluir que o acesso aos recursos e a ação tomada a partir da oportunidade identificada são fundamentais para a atividade empreendedora (Alvarez \& Busenitz, 2001; Fisher, 2012). Por outro lado, conforme argumentam Fisher (2012) e Sarasvathy (2001), o indivíduo que já possui recursos tem maiores chances de atuar sobre uma oportunidade do que aquele que não os possui.

\section{Empreendedorismo sustentável enquanto empreendedorismo institucional}

O empreendedor sustentável, ainda que possa ter acesso a recursos valiosos, encontra outras dificuldades não só para mobilizar esses recursos como também para convencer stakeholders do potencial do seu negócio (Ceschin, 2013; Karakaya, Hidalgo e Nuur, 2014). As inovações criadas por esses empreendedores enfrentam barreiras corporativas na medida em que elas exigem alterações significativas na cultura e na estrutura da organização e altos investimentos em maquinário, sem a contrapartida de certeza de fluxo de caixa esperado, dada a incerteza que envolve a adoção dessas inovações (Ceschin, 2013). Outra barreira que esses empreendedores enfrentam é na aceitação do seu produto/serviço por parte dos consumidores, já que exigem deles mudanças cognitivas-culturais. Como consequência, essas barreiras impedem a disseminação e tornam a inovação compatível apenas para alguns nichos de mercado (Ceschin, 2013).

As barreiras que esses empreendedores enfrentam estão, portanto, ligadas à necessidade de legitimidade e de mudanças normativas e cognitivas-culturais que permitam a difusão de seus negócios, tornando-os empreendedores institucionais (Pacheco, Dean e Payne, 2010; Thompson, Herrmann e Hekkert, 2015). Nesse sentido, a teoria institucional pode contribuir para desvendar as estratégias utilizadas por empreendedores sustentáveis para superar essas barreiras institucionais.

Dentro da teoria institucional, o tema do empreendedorismo institucional é relativamente pouco estudado (Bruton et al, 2010; Pacheco et al., 2010; Su, Zhai e Karlsson, 2016), havendo uma predominância de pesquisas que abordam o comportamento homogêneo e isomórfico das organizações, oriundo da necessidade de conformidade destas às regras e normas construídas por meio da constante interação de um determinado grupo de organizações reunidas em torno de um tema comum (DiMaggio \& Powell, 1991; Hoffman, 1999). Estas regras e normas que produzem comportamentos rotineiros e entranhados de tal forma que são custosos de se abrir mão são denominadas de instituições (Scott, 2013); o grupo de organizações 
que compartilha esses valores e regras é conhecido como campo organizacional, conceito que apresenta diferentes abordagens na literatura (Machado-da-Silva, Guarido Filho e Rossoni, 2006).

A vertente do empreendedorismo institucional surgiu como resposta às críticas à teoria institucional sobre seu pressuposto de estabilidade das instituições (Dacin, Goodstein e Scott, 2002), sem se levar em conta de que estas também são passíveis de mudanças. DiMaggio (1988) expande a teoria ao incluir a agência do ator social na criação e modificação das instituições, estabelecendo o paradoxo da 'agência imbricada' dentro da teoria institucional. Neste paradoxo, que reflete o embate entre estrutura e agência, "os atores estão sujeitos a processos regulatórios, normativos e cognitivos que estruturam suas cognições, definem seus interesses e produzem suas identidades" (Garud, Hardy e Maguire, 2007, p. 961). Porém, ao mesmo tempo, são capazes de criar novos processos e persuadir outros a adotá-los (Battilana, Leca e Boxenbaum, 2009). Os agentes de mudança que contribuem para transformações institucionais de um campo são conhecidos como empreendedores institucionais (Battilana, Leca e Boxenbaum, 2009; DiMaggio, 1988).

Neste processo de agência, os atores criam oportunidades através da sua interação com o ambiente físico e social onde estão inseridos e mobilizam recursos para alterar as estruturas organizacionais existentes de modo que passem a refletir seus interesses (DiMaggio, 1988; Battilana, Leca e Boxenbaum, 2009). Desse modo, a mudança institucional passa a ser um processo político, no qual o poder e os interesses dos atores sociais iniciam o processo de mudança (Maguire, Hardy e Lawrence, 2004).

A pesquisa em empreendedorismo institucional possui abordagens distintas, provenientes da economia e da sociologia: a primeira possui ênfase na racionalidade e nos interesses econômicos do empreendedor; a segunda abrange questões sociais e culturais (Pacheco et al., 2010). É importante notar que, na pesquisa em empreendedorismo tradicional, ou seja, na pesquisa sobre empresas nascentes, a abordagem econômica é a mais comumente utilizada (Pacheco et al., 2010). A presente pesquisa, no entanto, utiliza a abordagem sociológica da teoria institucional, pelo fato de os empreendedores sustentáveis lidarem especialmente com barreiras sociais e culturais para difusão de seus produtos/serviços.

Para Battilana, Leca e Boxenbaum (2009), os empreendedores institucionais podem ser comparados com o conceito tradicional de empreendedor, com a ressalva de que só aqueles cujos novos modelos de negócios apresentem divergência dos existentes podem ser considerados empreendedores institucionais. De forma análoga, nem todos os empreendedores institucionais são empreendedores, já que a criação de um novo negócio não constitui a base do empreendedorismo institucional.

Para Battilana, Leca e Boxenbaum (2009), dois tipos de fatores permitem os processos de mudança institucional: 1) a posição social dos atores envolvidos e 2) as características ou a estruturação do campo organizacional. A posição social do ator interfere no processo de mudança; atores com maior acesso a recursos ou mais bem situados na rede social estão em melhores condições para modificar as instituições (Battilana, Leca e Boxenbaum, 2009). A bagagem profissional e social que o ator social carrega, construída socialmente e legitimada em um campo, também traz a legitimidade necessária para atrair recursos e stakeholders para o processo de mudança (Maguire, Hardy e Lawrence, 2004; Pacheco, Dean e Payne, 2010). A centralidade dos atores dentro do campo organizacional também influencia o processo de empreendedorismo institucional: quanto mais central e integrado o ator se posiciona, menos ele questiona as normas e regras correntes, ao contrário de um ator mais periférico, que pode questioná-las com mais facilidade (Maguire, Hardy e Lawrence, 2004; Greenwood \& Suddaby, 2006; Pacheco, Dean e Payne, 2010). 
As características do campo organizacional também permitem processos de mudanças institucionais. Quanto mais institucionalizado um campo for, por exemplo, mais estáveis e incorporados são os padrões e normas estabelecidos, dificultando seu questionamento (David, Sine e Haveman, 2013; Greenwood \& Suddaby, 2006). Em campos menos maduros, como é o caso dos empreendedores sustentáveis, maiores são os esforços de legitimação, já que carecem de legitimidade cognitiva e sociopolítica. A primeira está relacionada ao quanto a nova prática pode ser considerada 'normal' pelos potenciais usuários e stakeholders, ao passo que a segunda se refere ao quanto essa nova prática se adequa aos padrões e regras aceitas pelo campo (Aldrich \& Fiol, 1994).

\section{Estratégias de legitimação e de mudança institucional}

A legitimidade pode ser adquirida através de estratégias desenvolvidas pelo empreendedor para a defesa de seus interesses. As seguintes estratégias foram verificadas na literatura em empreendedorismo institucional e empreendedorismo sustentável:

- Teorização: a implementação de mudanças institucionais se dá através da criação de uma visão que possa mobilizar outros stakeholders para as mudanças divergentes desejadas. A criação dessa visão se dá por meio da construção de cadeias de causa e efeito que explicam o porquê de se adotar um determinado conceito e de se deixar de utilizar outro (Battilana, Leca e Boxenbaum, 2009; Greenwood, Suddaby e Hinings, 2002). Dessa forma, a teorização provê uma justificativa para a mudança, permitindo a explicação das novas práticas e de seus benefícios, sempre comparada com as práticas vigentes. A teorização se dá através do enquadramento (framing) dos problemas, especificando um fracasso organizacional que clama por mudança; e da justificativa para a inovação, legitimando os valores propostos pelos empreendedores institucionais (Greenwood, Suddaby e Hinings, 2002). Fundamental para a teorização é a forma com que esses empreendedores conseguem alinhar o seu discurso e seus projetos de mudança com os interesses dos outros atores do campo (Maguire, Hardy e Lawrence, 2004).

- Construção de organizações de interesse coletivo: a teorização, no entanto, não é suficiente para o convencimento e a mobilização de outros atores para a causa, já que interesses pessoais do empreendedor podem ser transparentes para outros atores e causar desconfiança (Tolbert, David e Sine, 2011). Como forma de resolver essa transparência, os empreendedores institucionais se utilizam de organizações coletivas, tais como associações de indústria e sistemas de certificação, implementando novas regras de conduta e regulamentações que legitimem suas ações (Greenwood, Suddaby e Hinings, 2002; Pacheco, Dean e Payne, 2010).

- Formação de redes colaborativas: o empreendedor institucional muitas vezes age através da mobilização de atores sociais dispersos, mas que compartilham interesses, significados e uma identidade coletiva (Pacheco et al., 2010). A construção de redes de colaboração entre esses diversos atores, feita através de táticas políticas como negociação, acordos e barganha, é outra forma de levar adiante as estratégias de teorização (Maguire, Hardy e Lawrence, 2004). 
- Construção de novas medidas específicas à indústria: esta estratégia foi identificada na pesquisa de Thompson, Herrmann e Hekkert (2015), que analisaram empreendedores sustentáveis da indústria holandesa de torrefação de biomassa. A construção de medidas, tais como economia de emissão de gases, teve como objetivo comunicar os benefícios das atividades da indústria e permitir sua rápida difusão.

- Geração de consenso: assim definido no estudo de Thompson, Herrmann e Hekkert (2015), essa estratégia envolve a atração de organizações de alta legitimidade, tais como organizações regionais e supranacionais da indústria, como forma de ganho adicional de legitimidade.

\section{METODOLOGIA}

A pesquisa em empreendedorismo institucional aborda a elaboração de novos significados construídos socialmente num campo organizacional (Pacheco et al., 2010). Para o entendimento de como as instituições são alteradas e como a ação de indivíduos provoca mudanças institucionais é indispensável o estudo, não só do fenômeno, mas do contexto social onde ele está inserido (Maguire, Hardy e Lawrence, 2004). Dessa maneira, o método utilizado para essa pesquisa foi o de estudo de caso (Yin, 2003), permitindo o entendimento do processo de montagem de um negócio e de seu contexto, desde a identificação da oportunidade até sua exploração. Para essa pesquisa, optou-se pela abordagem de múltiplos estudos de caso, visando a uma análise comparativa da ação empreendedora em campos organizacionais originados direta ou indiretamente pelo movimento ambiental no país e que possibilitasse a emergência de padrões de relações entre as categorias conceituais intra e inter casos. De acordo com Yin (2003) e Eisenhardt \& Graebner (2007), os múltiplos estudos de caso oferecem uma base mais robusta para a construção de teorias.

Foram realizadas entrevistas em profundidade, semi-estruturadas, com duração de 40 minutos a uma hora e meia com os responsáveis por cada empresa. Fontes secundárias e entrevistas com stakeholders foram utilizadas como forma de triangulação de dados. As entrevistas foram realizadas no local de trabalho ou na residência dos entrevistados, presencialmente ou por telefone. As entrevistas seguiram um roteiro que direcionou as perguntas de acordo com as principais categorias conceituais existentes na literatura (Eisenhardt, 1989) em relação aos mecanismos da ação empreendedora (causation, effectuation e bricolagem) e às estratégias de legitimação e convencimento de stakeholders (teorização, formação de redes colaborativas, entre outras).

A unidade de análise do estudo foi a ação empreendedora (Fisher; 2012), traduzida na formação de uma nova empresa ou de um novo negócio dentro de uma empresa já existente. As empresas selecionadas para esse estudo obedeceram a quatros critérios: 1) seus negócios apresentavam inovações relativas ao produto/serviço ou ao modelo de negócios ou a um novo mercado; 2) se propunham a resolver problemas ambientais e/ou sociais, mas também com objetivo de geração de riqueza econômica; 3) seus produtos/serviços ou modelos de negócios apresentavam divergência dos produtos/serviços ou modelos predominantes e 4) seus negócios propunham novas instituições, novos hábitos ou novas formas de se pensar. Os três casos selecionados diferiam entre si pela motivação (mais comercial ou mais social) e pela 'independência', ou seja, se eram negócios independentes ou se eram casos de intraempreendedorismo. $O$ Quadro 1 detalha os casos selecionados. 
Quadro 1- Casos selecionados

\begin{tabular}{|c|c|c|c|c|c|}
\hline Empresa & Tipo & Desde & Área & Entrevistas & Fontes secundárias \\
\hline CBpak & $\begin{array}{l}\text { Com fins } \\
\text { lucrativos }\end{array}$ & 2002 & $\begin{array}{l}\text { Comercialização de } \\
\text { embalagens } \\
\text { biodegradáveis e } \\
\text { compostáveis feitas de } \\
\text { mandioca. }\end{array}$ & $\begin{array}{l}\text { Empreendedor/ } \\
\text { funcionários: } 2 \\
\text { Parceiro: } 1 \\
\text { Cliente: } 1\end{array}$ & $\begin{array}{l}\text { Documentos da } \\
\text { empresa, mídia, etc. } \\
\text { Total: } 14\end{array}$ \\
\hline $\begin{array}{l}\text { Ciclo } \\
\text { Orgânico }\end{array}$ & $\begin{array}{l}\text { Negócio } \\
\text { social com } \\
\text { fins } \\
\text { lucrativos }\end{array}$ & $2015 / 2016$ & $\begin{array}{l}\text { Serviço de coleta de lixo } \\
\text { orgânico em residências } \\
\text { e pequenas empresas } \\
\text { para compostagem e } \\
\text { retorno na forma de } \\
\text { adubo orgânico. }\end{array}$ & $\begin{array}{l}\text { Empreendedor/ } \\
\text { funcionários: } 2 \\
\text { Parceiros: } 2 \\
\text { Clientes: } 2\end{array}$ & $\begin{array}{l}\text { Documentos da } \\
\text { empresa, mídia, } \\
\text { entrevistas feitas por } \\
\text { terceiros, etc. } \\
\text { Total: } 25\end{array}$ \\
\hline $\begin{array}{l}\text { Circulare / } \\
\text { Empresa } \\
\text { Verde }^{*}\end{array}$ & $\begin{array}{l}\text { Com fins } \\
\text { lucrativos }\end{array}$ & $\begin{array}{l}2014 \\
\text { (Circulare) }\end{array}$ & $\begin{array}{l}\text { Serviço de coleta de } \\
\text { equipamentos } \\
\text { (resíduos) para } \\
\text { transformação em } \\
\text { materiais que sirvam } \\
\text { como matéria-prima } \\
\text { para a indústria. }\end{array}$ & $\begin{array}{l}\text { Empreendedor/ } \\
\text { funcionários: } 4 \\
\text { Parceiro: } 1 \\
\text { Clientes: } 1\end{array}$ & $\begin{array}{l}\text { Documentos da } \\
\text { empresa, mídia, } \\
\text { palestras, etc. } \\
\text { Total: } \mathbf{2 9}\end{array}$ \\
\hline
\end{tabular}

*nomes fictícios adotados, por solicitação do gestor do novo negócio na empresa.

Fonte: Elaborado pelos autores

Todas as entrevistas foram gravadas e transcritas, mediante a autorização dos entrevistados. Das empresas entrevistadas, apenas uma solicitou que não se revelasse o nome dos entrevistados, tampouco o da empresa. A Empresa Verde e sua unidade Circulare são, por conseguinte, nomes fictícios. O campo organizacional em que esses empreendedores atuam é o da sustentabilidade corporativa, ou seja, das empresas que incorporam conceitos ligados ao desenvolvimento sustentável em suas operações.

Os dados das entrevistas foram analisados por meio do software Atlas.ti 8.0, juntamente com os documentos de fontes secundárias. A codificação e análise dos dados foram feitas num processo iterativo, conforme sugerido por Eisenhardt (1989). Cada caso foi analisado separadamente e, por fim, foi feita uma análise comparativa entre os casos, identificando-se padrões entre eles. Por razões de espaço, a análise apresentada neste artigo é a intercasos.

A CBPak é a mais antiga das três selecionadas, com quase 15 anos de atuação, sendo que 5 dedicados apenas ao desenvolvimento da tecnologia. A empresa atende pequenas, médias e grandes empresas e o campo organizacional onde atua é o da "sustentabilidade corporativa", ou seja, empresas que possuem algum tipo de preocupação relativa ao desenvolvimento sustentável. Atualmente, a CBPak, ao oferecer embalagens descartáveis e compostáveis feitas de mandioca, tenta mudar as instituições desse campo através do conceito de economia circular divulgado pela Fundação Ellen MacArthur. No entanto, a empresa ainda enfrenta a resistência do mercado quanto ao preço do produto/serviço, o que indica que a percepção de valor sobre a questão ambiental ainda não foi estabelecida mesmo dentro do campo de empresas ambientalmente conscientes. 
O Ciclo Orgânico, por sua vez, atende principalmente pessoas físicas, embora atenda algumas empresas de pequeno porte. Outra distinção dessa empresa é sua motivação, sendo predominantemente social, de forma que é considerada como um negócio social tanto pelo empreendedor como pela rede de organizações com as quais a empresa tem relações, como o programa Iniciativa Jovem, a organização sem fins lucrativos BrazilFoundation, entre outras. Com dois anos de atuação, a empresa oferece a coleta privada de lixo orgânico de residências, levando-o a centros próprios de compostagem, onde produz composto orgânico. As mudanças cognitivo-culturais propostas pelo serviço são relativas à existência de coleta de lixo gratuita efetuada pelas prefeituras. A empresa faz parte do campo de empresas de jovens empreendedores, muitas vezes recém-saídos de cursos de engenharia ambiental e ligados a grupos de agrofloresta e permacultura, configurando um campo organizacional emergente.

O terceiro caso, o da Circulare, compartilha com o primeiro a utilização do conceito de economia circular e tem como característica ser um novo negócio de uma empresa já estabelecida, a Empresa Verde, constituindo um exemplo de intraempreendedorismo. A Circulare completa três anos em 2017, respaldada pela atuação de mais de 40 anos da Empresa Verde, sendo esta uma empresa ambientalmente consciente com exposição internacional de mais de duas décadas, inserindo-se no campo de sustentabilidade corporativa no Brasil e no mundo. Seus produtos/serviços - coleta de aparelhos recicláveis e comercialização de insumos reciclados para a indústria - enfrentam barreiras institucionais também relativas a preço, no lado da coleta de aparelhos, e de qualidade, no lado da comercialização de reciclados.

A presente pesquisa apresenta limitações metodológicas de subjetividade inerentes às pesquisas qualitativas e ao fato dos stakeholders entrevistados para triangulação dos dados terem sido indicados pelos próprios empreendedores, possibilitando a existência de vieses favoráveis aos casos estudados.

\section{APRESENTAÇÃo E ANÁLISE dOS RESULTADOS}

\section{Identificação da oportunidade}

$\mathrm{Na}$ lógica de effectuation, existem três tipos de categorias de recursos ou meios de onde partem os empreendedores: "eles sabem quem eles são, o que eles sabem e quem eles conhecem (Sarasvathy, 2001, p. 250). Ou seja, as características particulares dos empreendedores, seu conhecimento técnico ou de mercado ou de experiência e suas redes de relacionamento são os elementos que o empreendedor acessa para que possa iniciar uma ação empreendedora. Tanto a CBPak quanto o Ciclo Orgânico partiram da lógica de effectuation na identificação da oportunidade, ao passo que a Empresa Verde teve como lógica principal a de causation, conforme pode ser visto no Quadro 2.

É interessante observar como o processo de identificação da oportunidade foi inverso nos dois casos dos empreendedores em comparação com o intraempreendedor (Verde): no primeiro caso, os empreendedores analisaram seus recursos internos para então buscar fontes que complementassem esses recursos; no caso do intraempreendedor, primeiro se olhou o mercado para depois verificar se a empresa possuía recursos internos para tornar a oportunidade concretizável. 
Quadro 2- Identificação da oportunidade

\begin{tabular}{|c|c|c|}
\hline Empresa & Mecanismo empreendedor & Relatos \\
\hline CBpak & $\begin{array}{l}\text { Recursos on hand (effectuation) } \\
\text { - Papel da experiência prévia (ex-executivo de } \\
\text { multinacionais, consultor no setor de } \\
\text { embalagens) } \\
\text { - Posição social (rede de contatos, status } \\
\text { social) } \\
\text { - Existência de um grupo de pesquisa } \\
\text { desenvolvendo a tecnologia }\end{array}$ & $\begin{array}{l}\text { "Eu reestruturei uma empresa de packaging, então } \\
\text { é público e notório que o plástico tem dias } \\
\text { contados. Fazer copinho de plástico com petróleo } \\
\text { não vai caber na cabeça de todo mundo, então as } \\
\text { pessoas vão ter que buscar alternativas." }\end{array}$ \\
\hline $\begin{array}{l}\text { Ciclo } \\
\text { Orgânico }\end{array}$ & $\begin{array}{l}\text { Recursos on hand (effectuation) } \\
\text { - Papel da experiência prévia (programa de } \\
\text { extensão na faculdade e estágio na área) } \\
\text { - Participação no programa Iniciativa Jovem, } \\
\text { complementando recursos (gestão e rede de } \\
\text { contatos) }\end{array}$ & $\begin{array}{l}\text { "Aí quando eu comecei a trabalhar na VideVerde, } \\
\text { que é empresa de compostagem de larga escala, } \\
\text { eu via que tinha gente que procurava a empresa } \\
\text { querendo o serviço para a residência." }\end{array}$ \\
\hline $\begin{array}{l}\text { Circulare / } \\
\text { Empresa } \\
\text { Verde * }^{*}\end{array}$ & $\begin{array}{l}\text { Lógica de causation } \\
\text { - Contratação de uma equipe externa, de } \\
\text { perfil empreendedor, } \\
\text { - Análise dos gaps de mercado; existência da } \\
\text { Política Nacional de Resíduos Sólidos e do } \\
\text { conceito de economia circular } \\
\text { Recursos on hand } \\
\text { - Experiência com logística reversa }\end{array}$ & $\begin{array}{l}\text { "A Empresa Verde tomou uma decisão de buscar } \\
\text { uma diversificação do seu negócio. Então, a gente } \\
\text { foi fazer um entendimento de quais eram os } \\
\text { desafios que a nossa indústria estava passando, } \\
\text {...e que a indústria dos nossos clientes estavam } \\
\text { passando referentes ao assunto sustentabilidade, } \\
\text { gestão de resíduos. Foi quando a gente se deparou } \\
\text { com a Política Nacional de Resíduos Sólidos, } \\
\text { aprovada em } 2010 \text {. Foi quando a gente identificou } \\
\text { essa tendência e falou: o nosso cliente tem esse } \\
\text { problema, que é a gestão do resíduo, que é a } \\
\text { gestão do produto em fim de vida." }\end{array}$ \\
\hline
\end{tabular}

Fonte: Elaborado pelos autores 


\section{Estratégias de mobilização de recursos e convencimento de stakeholders}

A análise comparativa dos casos foi feita com base: 1) na forma com que os empreendedores alcançavam legitimidade para acessar os recursos de terceiros; 2) na mobilização de recursos e 3 ) nas estratégias utilizadas para realizar mudanças institucionais, entendidas como a forma com que esses empreendedores conquistam clientes e aceitação social de forma mais ampla para seus negócios.

\section{Legitimidade}

Para a conquista de legitimidade para seus negócios na busca por recursos financeiros, físicos e humanos os empreendedores se utilizam, intencionalmente ou não, das seguintes estratégias:

- Posição social e recursos on hand: tanto a CBPak como o Ciclo Orgânico se utilizaram das lógicas de effectuation para a conquista de legitimidade dos seus negócios, no sentido de ativarem seus recursos on hand, ou seja, seus recursos pré-existentes. A posição social do empreendedor (Maguire, Hardy e Lawrence, 2004) encontra equivalente na lógica de effectuation do 'quem sou eu', 'o que eu sei' e 'quem eu conheço' (Sarasvathy, 2001). Após acionar esses recursos que os legitimam, os empreendedores conseguem conquistar outros recursos que aumentam a legitimidade dos empreendedores e de seus negócios, como a parceria com uma universidade no caso da CBPak e de um parque público para compostagem no caso do Ciclo Orgânico.

- Lógica de causation: a Empresa Verde não necessita de conquista de legitimidade por possuir 40 anos de existência e ser vastamente reconhecida no meio. No entanto, os executivos da empresa precisam conquistar legitimidade interna quanto à validade do seu negócio, o que foi feito com a contratação de profissionais com perfil de empreendedor para identificar oportunidades e explorá-las. Essa defesa é feita primordialmente através de uma lógica de causation, com a análise de gaps de mercado, de tendências do mercado consumidor, do tamanho do mercado no país, da infraestrutura da indústria e da política nacional de resíduos sólidos, da existência da lei, entre outras.

É interessante observar que a CBPak e o Ciclo Orgânico também utilizaram a lógica de causation no processo de legitimação. No caso do empreendedor da CBPak, esses elementos de causation foram utilizados para aporte financeiro por outras empresas; para o Ciclo Orgânico, a lógica de causation era condição para obtenção do selo do programa de capacitação. Essa legitimidade é oriunda justamente da utilização de uma lógica de causation que é consonante com os valores dos atores do campo das corporações em geral. 
Lógica empreendedora na mobilização de recursos

Todos os três casos analisados utilizaram-se, em menor ou maior grau, da lógica de effectuation na condução de seus negócios, embora essa lógica tenha sido verificada com maior frequência nos casos da CBPak e do Ciclo Orgânico. É importante constatar que as lógicas de effectuation e bricolagem compartilham de elementos similares conceitualmente, o que foi verificado também nos dados. Conforme argumenta Fisher (2012), esses elementos compartilhados se referem especialmente aos recursos pré-existentes como imprescindíveis para a ação empreendedora, à forma coletiva de se criar um negócio e à limitação de recursos como fonte de criatividade. No entanto, a bricolagem está mais relacionada a situações de penúria, sendo verificada em maior grau no Ciclo Orgânico. Parte da explicação advém da sua maior limitação de recursos, exigindo do empreendedor maior criatividade e maior capacidade de 'fazer acontecer com o que se tem em mãos'.

Os empreendedores da CBPak e do Ciclo Orgânico utilizaram recursos de habilidades autodidatas, parcerias com outras organizações antes de a solução estar completa, envolveram suas famílias nos negócios provendo habilidades, desenvolveram suas soluções num processo de experimentação e aprendizado iterativo e limitaram seus gastos às receitas. Em menor grau, a Empresa Verde também desenvolveu sua solução de forma experimental e aprendendo com a experiência com sua carteira de clientes já existente. A lógica de causation foi verificada compreensivelmente em maior grau na Empresa Verde já que o novo negócio precisa estar em conformidade com as regras da empresa. No entanto, o Ciclo Orgânico também se utilizou dessa lógica em conjunto com as lógicas de effectuation e de bricolagem, refletindo sua dependência em relação ao programa de capacitação, que condiciona sua legitimidade à adoção e cumprimento de um plano de negócios. Nesse sentido, a lógica de causation dentro de um empreendimento com orientação mais social remete a um processo de isomorfismo coercitivo, em que relações de poder entre duas organizações têm como consequência a similaridade nas práticas organizacionais (DiMaggio \& Powell, 1991). Outra explicação é o fato de o empreendedor do Ciclo Orgânico ser jovem e ter pouca experiência como empreendedor. Já o empreendedor da CBPak, com vasta experiência no mercado e como empreendedor, tem maior facilidade em acessar seu conhecimento anterior e sua intuição para a tomada de decisão, seguindo com maior frequência a lógica de effectuation, corroborando os argumentos de Welter, Mauer \& Wuebker (2016) sobre a abordagem de effectuation na ação empreendedora.

\section{Estratégias de mudança institucional}

As estratégias de convencimento de stakeholders e de mudanças institucionais verificadas nos três casos foram a teorização, com enquadramento do problema e a justificativa da inovação; a utilização de redes de colaboração para engajar mais stakeholders e aumentar a legitimidade do negócio; o alinhamento com stakeholders de alta legitimidade e a participação em palestras, eventos, prêmios e exposição na mídia:

- Teorização: os três casos estudados buscam atrair mais stakeholders ao seu negócio através da teorização (Greenwood, Suddaby e Hinings, 2002; Maguire, Hardy e Lawrence, 2004). A forma de argumentação de empreendedores institucionais nessa teorização inclui a incorporação de valores 
que atendam a diversos stakeholders, de forma a atrair mais apoio à sua causa. $\mathrm{O}$ interessante na análise dos argumentos dos três casos é a importância dada às métricas dos impactos benéficos ao meio ambiente resultantes da adoção da sua solução, conforme verificaram Thompson, Herrmann e Hekkert (2015) com empreendedores sustentáveis da indústria holandesa de torrefação de biomassa. Na presente pesquisa, no entanto, essa metrificação foi percebida como uma adoção da lógica de causation, atendendo aos valores dos stakeholders que se pretende atrair e justificando sua existência na mesma linguagem dos outros atores do campo organizacional. Por ser a CBPak a empresa com maior tempo de atividade dentro os três casos estudados, foi possível identificar no seu caso a aplicação da lógica de effectuation na sua prática de teorização, por meio da experimentação e do aprendizado iterativo em seu discurso, à medida que emergiam necessidades por parte de clientes conforme o contexto.

- Alinhamento com stakeholders de alta legitimidade: nos três casos, a parceria com uma organização de renome internacional com alta legitimidade possui impactos sobre a própria legitimidade do negócio, aumentando seu poder de convencimento de stakeholders para a adoção de suas soluções, semelhante à pesquisa de Thompson, Herrmann e Hekkert (2015).

- Redes de colaboração: nos três casos estudados, esse alinhamento também permitiu o acesso a uma rede de colaboração em torno da organização de renome. Tanto a CBPak quanto a Empresa Verde passaram a fazer parte da rede de colaboração da economia circular da Fundação Ellen MacArthur, empresa que promove a economia circular no Brasil e no mundo. O empreendedor do Ciclo Orgânico, através da participação no programa Iniciativa Jovem passou a fazer parte da rede de contatos do programa. Essas redes permitem a ação coletiva de empresas para transformações institucionais em torno de um tema, sem que se questione os interesses embutidos nos argumentos individuais de organizações (Garud, Jain e Kumaraswamy, 2002; Lawrence, Hardy e Phillips, 2002; Maguire, Hardy e Lawrence; 2004). Adicionalmente, essas redes permitem a troca de informações, geração de conhecimento e complementação de recursos.

- Participação em palestras e eventos, prêmios e exposição na mídia: a participação nessas redes também tem como consequência uma maior exposição na forma de palestras e eventos, maior chance de ganhar prêmios de organizações legitimadoras e maior exposição na mídia. Essas estratégias surgem em consequência das anteriores, mas merecem destaque já que se tratam de novos negócios e, como tal, demandam estratégias de marketing para que sejam conhecidas, legitimadas e, por fim, adotadas. Neste sentido, as estratégias para mudanças institucionais de empresas novas entrantes estão altamente vinculadas com as estratégias de marketing das empresas de uma forma geral. O Quadro 3 resume e exemplifica os principais dados analisados acima. 
Quadro 3- Estratégias de mobilização de recursos e convencimento de stakeholders

continua

\begin{tabular}{|c|c|c|}
\hline Objetivo & Mecanismo da ação empreendedora & Relatos \\
\hline \multicolumn{3}{|c|}{ Legitimidade } \\
\hline CBpak & $\begin{array}{l}\text { Posição social do ator/ recursos on hand: ex- } \\
\text { executivo de multinacionais e consultor; recursos } \\
\text { financeiros próprios; parceria com universidade } \\
\text { Causation: VPL, modelo de negócios para atrair } \\
\text { stakeholders }\end{array}$ & \multirow{3}{*}{$\begin{array}{l}\text { CBPak: "Quando hoje você fala assim, como é que } \\
\text { você conseguiu quatro milhões de dólares para botar } \\
\text { no seu negócio com terceiros? Porque o cara olhou } \\
\text { para mim e falou assim, 'o cara botou um milhão do } \\
\text { bolso dele." } \\
\text { Ciclo Orgânico: "E aí fiz pesquisa de mercado, } \\
\text { comecei a prototipar, a atender algumas pessoas, fiz } \\
\text { o projeto piloto para entender, a escrever o plano de } \\
\text { negócios. E aí do meio para o final de } 2015 \text { que a } \\
\text { gente de fato começou a operar assim. (...) a } \\
\text { iniciativa jovem é fundamental, (...), qualquer } \\
\text { problema que você tem, (...) você manda email e as } \\
\text { pessoas ajudam, te dão monitoria,..." }\end{array}$} \\
\hline $\begin{array}{l}\text { Ciclo } \\
\text { Orgânico }\end{array}$ & $\begin{array}{l}\text { Posição social do ator/recursos on hand: } \\
\text { participação no programa Iniciativa Jovem e } \\
\text { categorização como empreendedor social; } \\
\text { parceria com parque do Martelo } \\
\text { Causation: VPL, modelo de negócios para atrair } \\
\text { stakeholders }\end{array}$ & \\
\hline $\begin{array}{l}\text { Empresa } \\
\text { Verde }\end{array}$ & $\begin{array}{l}\text { Causation (legitimidade interna): contratação de } \\
\text { uma equipe externa, análise dos gaps de } \\
\text { mercado; plano nacional de resíduos sólidos e } \\
\text { economia circular }\end{array}$ & \\
\hline \multicolumn{3}{|c|}{ Mobilização de recursos } \\
\hline CBF & $\begin{array}{l}\begin{array}{l}\text { Effectuation e bricolagem: } \\
\text { funcionária (bricolagem); parceria com }\end{array} \\
\text { universidades (effectuation e bricolagem); } \\
\text { experimentação e aprendizado iterativo na } \\
\text { montagem do negócio (effectuation); realização de } \\
\text { testes com a tecnologia acionando rede de } \\
\text { contatos (effectuation) }\end{array}$ & $\begin{array}{l}\text { Empresa Verde: "Quando a gente aprovou a criação } \\
\text { do negócio a gente tinha uma ideia, um conceito com } \\
\text { o seu business case atrelado e o seu VLP, mas à } \\
\text { medida que você vai implementando, você vai } \\
\text { também aprendendo algumas lições que mudam } \\
\text { aquele conceito original(...). A gente costuma dizer } \\
\text { que as empresas de pequeno porte, né, as empresas }\end{array}$ \\
\hline & $\begin{array}{l}\text { Effectuation e bricolagem: utilização dos } \\
\text { recursos próprios como insumos de trabalho e de } \\
\text { skills (bricolagem); parcerias feitas antes mesmo } \\
\text { do desenvolvimento do negócio (effectuation e } \\
\text { bricolagem); horas extras do empreendedor } \\
\text { dedicadas ao negócio (bricolagem) } \\
\text { Causation: obtenção do selo anual do programa } \\
\text { Iniciativa Jovem }\end{array}$ & $\begin{array}{l}\text { startup elas costumam ter um processo que é } \\
\text { chamado de pivotar. Ela desce até o mercado, } \\
\text { interage com o cliente, aprende as lições } \\
\text { devidamente, aprende as lições que tem que } \\
\text { aprender e se precisar mudar de rota ela muda de } \\
\text { rota rapidamente." }\end{array}$ \\
\hline $\begin{array}{l}\text { Empresa } \\
\text { Verde }\end{array}$ & $\begin{array}{l}\text { Effectuation: experimentação e aprendizado } \\
\text { iterativo com o serviço } \\
\text { Causation: reporte e conformidade às normas da } \\
\text { empresa (controles gerenciais) }\end{array}$ & \\
\hline
\end{tabular}




\begin{tabular}{|c|c|c|}
\hline Objetivo & Mecanismo da ação empreendedora & Relatos \\
\hline \multicolumn{3}{|c|}{ Convencimento de stakeholders e mudanças institucionais } \\
\hline CBPak & $\begin{array}{l}\text { Teorização: argumentos da economia circular e } \\
\text { elementos de causation (criação de métricas) } \\
\text { Effectuation na teorização do negócio promovido, } \\
\text { alterando e adaptando seu discurso à medida em } \\
\text { que novos fatores ambientais e novos conceitos } \\
\text { surgiam }\end{array}$ & $\begin{array}{l}\text { CBPak: "Já tem como metrificar o carbono. E o } \\
\text { mais importante que é o aterro sanitário, quanto } \\
\text { custa? E a compostagem, o quanto você pode } \\
\text { gerar de terra? (...). Então, essa é a conta, esse é } \\
\text { o valor de que nós carregamos conosco como } \\
\text { argumentos de vendas }(\ldots) \text {, já é uma coisa }\end{array}$ \\
\hline $\begin{array}{l}\text { Ciclo } \\
\text { Orgânico }\end{array}$ & $\begin{array}{l}\text { Teorização: semelhante à economia circular e } \\
\text { elementos de causation: criação de métricas }\end{array}$ & $\begin{array}{l}\text { eminentemente técnica em que você tem que } \\
\text { mostrar através da matemática, trazendo o }\end{array}$ \\
\hline $\begin{array}{l}\text { Empresa } \\
\text { Verde }\end{array}$ & $\begin{array}{l}\text { Teorização: argumentos da economia circular e } \\
\text { elementos de causation (criação de métricas na } \\
\text { teorização sobre o problema que a solução do } \\
\text { empreendedor tenta resolver) }\end{array}$ & $\begin{array}{l}\text { ambiental, o econômico, o social e o cultural, que } \\
\text { tem um grande ganho." } \\
\text { Ciclo: "A gente entende que para que de fato a } \\
\text { gente fechar o ciclo e promover essa } \\
\text { conscientização ambiental a gente informa qual foi } \\
\text { o impacto da ação de cada um. Então eu vou te } \\
\text { mandar um e-mail: "você compostou } 40 \text { quilos de } \\
\text { resíduos orgânicos, isso destinou } 25 \text { quilos de } \\
\text { adubo, evitou a emissão de } 30 \text { quilos de CO2(...). } \\
\text { O argumento é de fato você estar deixando de(...) } \\
\text { impactar negativamente o planeta." }\end{array}$ \\
\hline
\end{tabular}

Fonte: Elaborado pelos autores

\section{DISCUSSÃO E CONCLUSÕES}

A primeira pergunta de pesquisa possui um enfoque predominante da pesquisa em empreendedorismo tradicional, ao questionar como empreendedores sustentáveis identificam, avaliam e decidem explorar as oportunidades de negócios. Os resultados da pesquisa corroboraram os papéis da experiência prévia e do conhecimento do ator social na descoberta da oportunidade (Shane, 2000; Shane \& Venkataraman, 2000), e da predominância da lógica de effectuation (Sarasvathy, 2001) na identificação da oportunidade por parte de empreendedores. Estes resultados corroboram também os resultados de Fisher (2012), que conclui existir uma relação entre os recursos sob a posse do empreendedor e o reconhecimento de uma oportunidade, ou seja, "as oportunidades que emergem quando um empreendedor se concentra nos recursos que já possui são mais acionáveis do que aquelas que são descobertas através de análise da indústria ou de mercado" (Fisher, 2012, p.23). O empreendedor pode identificar uma oportunidade; porém, se não possuir os recursos para agir sobre ela, ele pode não ir adiante (Sarasvathy, 2001; Fisher, 2012).

A identificação da oportunidade dentro da Empresa Verde, no entanto, revelou um híbrido de lógicas de causation e effectuation, o que pode significar que a lógica de empreendedores é diferente da de intraempreendedores que, por sua vez, possuem lógica diferente da de gestores de empresas. Por outro lado, ao longo das outras perguntas de pesquisa, revelou-se que tanto empreendedores como intraempreendedores se utilizam de um misto de lógica de causation e de effectuation, o que corrobora os resultados das pesquisas de Fisher (2012) e Reymen et al. (2015), de que existe variação na lógica utilizada 
pelo empreendedor conforme o contexto em que este se encontra. Nesta pesquisa, ficou claro que o contexto para a utilização da lógica de causation pelo empreendedor é o de ganho de legitimidade.

A segunda pergunta da pesquisa - 'Como os empreendedores sustentáveis mobilizam e combinam recursos para explorar essas oportunidades?'- foi analisada em conjunto com a terceira pergunta,- 'De que forma esses empreendedores sustentáveis tentam modificar as instituições vigentes ou criar novas para que reflitam seus interesses particulares e organizacionais?'. Ao combinar as duas perguntas em uma mesma análise, foi possível constatar a contribuição dos mecanismos da ação empreendedora para as estratégias de legitimação e de mudança da teoria institucional e vice-versa. Para mobilizar recursos de terceiros, os empreendedores sustentáveis precisam adquirir a legitimidade necessária dentro dos seus campos para que haja confiança na sua atuação e na sua capacidade de prover serviços, de honrar empréstimos, de cumprir compromissos, entre outros, conforme explicam Aldrich \& Fiol (1994).

Nas estratégias para mudanças institucionais, verificou-se que esses empreendedores sustentáveis, tal e qual as pesquisas com empreendedores sustentáveis institucionais, se utilizam de elementos como teorização, alinhamento com stakeholders de alta legitimidade e participação em redes colaborativas (Thompson, Herrmann e Hekkert, 2015). Como complemento à literatura e, considerando empreendedores institucionais de empresas novas entrantes, verificou-se também a participação em eventos, palestras, o alcance de prêmios e exposição na mídia como formas de convencimento de stakeholders. Dessa maneira, as estratégias de convencimento desses empreendedores sustentáveis são parte das suas estratégias de marketing.

Outra questão levantada foi a utilização da metrificação como forma de justificativa para a inovação, dentro da estratégia de teorização. Nesse sentido, a metrificação representa os valores dos stakeholders que se deseja atender, revelando a utilização da lógica de causation dentro da teorização. Essa constatação corrobora os argumentos de Greenwood, Suddaby e Hinings (2002) e Maguire, Hardy e Lawrence (2004). Como os empreendimentos estudados eram empresas, a emergência de uma lógica de causation como legitimadora e promotora da mudança é consonante com as características do campo organizacional, em que métricas, resultados e desempenho são condição-chave para dele participar.

A classificação desses empreendedores sustentáveis como institucionais pode ser questionada sob uma ótica internacional, de conformidade desses empreendedores a uma nova forma de se fazer e pensar negócios, oriunda dos países desenvolvidos, consonante com o que Child, Lu e Tsai (2007) observaram em relação à criação de um sistema de proteção ambiental governamental na China, influenciada pela ONU. Ou seja, esses empreendedores podem estar se conformando às regras e normas existentes de grupos de atores sociais advindos de outras regiões tidas como mais legítimas. No entanto, o fato de os três empreendedores analisados ainda lidarem com barreiras institucionais para a difusão dentro do mercado nacional, fez com que fossem considerados nesta pesquisa como empreendedores institucionais.

Com base nas análises anteriores, entende- se que uma contribuição importante dessa pesquisa foi a análise de empreendedores sustentáveis e suas ações empreendedoras conforme uma ótica institucional, mas que, ao mesmo tempo, leva em conta a ótica tradicional de empreendedorismo. O destaque para as estratégias para conquista de legitimidade na mobilização de recursos e no convencimento de stakeholders é particularmente importante na pesquisa em empreendedorismo, na medida em que o acesso a recursos é essencial para a atividade empreendedora (Alvarez e Busenitz, 2001). Da mesma forma, para 
empreendedores institucionais e de novos negócios, o entendimento da lógica institucional do campo organizacional que pretendem alterar são relevantes na análise de suas estratégias de mudança.

A principal contribuição da adoção da teoria institucional nesta pesquisa foi a constatação de que o contexto em que esses empreendedores variam sua lógica de effectuation para causation está relacionado ao ganho de legitimidade e à tentativa de mudança institucional. Outra contribuição, dessa vez da abordagem em empreendedorismo para a teoria institucional, foi a constatação de que os argumentos da teorização podem apresentar variações ao longo do tempo, conforme a experimentação e aprendizado iterativo dos empreendedores, seguindo uma lógica de effectuation, à medida que novos desafios e oportunidades surjam que exijam adequação dos argumentos de teorização pelo empreendedor.

Para empreendedores sustentáveis que lidam com mudanças divergentes, a pesquisa pode servir como insumo para a formulação de estratégias que auxiliem na conquista de legitimidade e de stakeholders para seus respectivos negócios, aumentando suas chances de sobrevivência e de promoção de algum tipo de impacto ambiental. Para gestores de políticas públicas, os resultados da pesquisa podem promover a reflexão sobre as formas de se incentivar a ação de empreendedores sustentáveis, na medida em que estes representam não só a possibilidade de desenvolvimento econômico, como também formas privadas de se diminuir os impactos ambientais sobre a sociedade. Esta pesquisa não é isenta de limitações. A ideia de campo organizacional e da atuação de outros atores dentro de cada campo foram pouco aprofundados na pesquisa, por não terem sido o escopo da mesma. Dessa forma, o que é o campo organizacional de cada empresa estudada, quais os atores sociais que pertencem a ele e como estes interagem foram questões pouco exploradas na pesquisa. Não obstante, esta limitação pode indicar novos caminhos de pesquisa tais como o estudo da formação espontânea de redes colaborativas por atores sociais dispersos advindos do setor privado, organizações sem fins lucrativos e órgãos governamentais dentro de um processo de empreendedorismo institucional. Pretende-se seguir esta trilha nas próximas pesquisas.

\section{REFERÊNCIAS}

ALDRICH, H. E.; FIOL, C. M. Fools rush in? The institutional context of industry creation. Academy of Management Review, v. 19, n. 4 , p. $645-670,1994$.

ALVAREZ, S. A.; BUSENITZ, L. W. The entrepreneurship of resource-based theory. Journal of Management, v. 27, n. 6, p. 755-775, 2001.

BAKER, T; NELSON, R. E. Creating something from nothing: Resource construction through entrepreneurial bricolage. Administrative Science Quarterly, v. 50, n. 3, p. 329-366, 2005.

BATTILANA, J; LECA, B; BOXENBAUM, E. How actors change institutions: towards a theory of institutional entrepreneurship. The Academy of Management Annals, v. 3, n. 1, p. 65-107, 2009.

BRUNELLI, M.; COHEN, M. Definições, Diferenças e Semelhanças entre Empreendedorismo Sustentável e Ambiental: Análise do Estado da Arte da Literatura entre 1990 e 2012. XXXVI Encontro da Associação Nacional de Pós-Graduação e Pesquisa em Administração, 2012.

BRUTON, G. D.; AHLSTROM, D; L.; LI, H. L. Institutional theory and entrepreneurship: where are we now and where do we need to move in the future? Entrepreneurship Theory and Practice, v. 34, n. 3, p. 421-440, 2010.

BUSENITZ, L. W.; PLUMMER, L. A.; KLOTZ, A. C.; SHAHZAD, A.; RHOADS, K. Entrepreneurship research (1985-2009) and the emergence of opportunities. Entrepreneurship Theory and Practice, v. 38, n. 5, p. 981-1000, 2014.

CESCHIN, F. Critical factors for implementing and diffusing sustainable product-Service systems: insights from innovation studies and companies' experiences. Journal of Cleaner Production, v. 45, p. 74-88, 2013.

CHILD, J.; LU, Y.; TSAI, T. Institutional entrepreneurship in building an environmental protection system for the People's Republic of China. Organization Studies, v. 28, n. 7, p 1013-1034, 2007. 
COOK, J.; ORESKES, N.; DORAN, P. T.; ANDEREG, W. R. L.; VERHEGGEN, B.; MAIBAC, E. W; CARLTON, J. S.; LEWANDOWSKY, S.; SKUCE, A.; GREEN, S. A. Consensus on consensus: a synthesis of consensus estimates on human-caused global warming. Environmental Research Letters, v. 11, n. 4, p. 048002, 2016.

DACIN, M. T.; GOODSTEIN, J.; SCOTT, W. R. Institutional theory and institutional change: Introduction to the special research forum. Academy of Management Journal, 45(1), 45-56, 2002.

DAVID, R. J.; SINE, W. D.; HAVEMAN, H. A. Seizing opportunity in emerging fields: How institutional entrepreneurs legitimated the professional form of management consulting. Organization Science, v. 24, n. 2, p. 356-377, 2013.

DAVIDSSON, P. Entrepreneurial opportunities and the entrepreneurship nexus: A re-conceptualization. Journal of Business Venturing, v. 30, n. 5, p. 674-695, 2015.

DEAN, T. J.; MCMULLEN, J. S. Toward a theory of sustainable entrepreneurship: Reducing environmental degradation through entrepreneurial action. Journal of Business Venturing, v. 22, n. 1, p. 50-76, 2007.

DIMAGGIO, P. J. Interest and agency in institutional theory. Institutional patterns and organizations: Culture and environment, v. 1, p. 3-22, 1988.

DIMAGGIO, P. J.; POWELL, W. W. The iron cage revisited: Institutional isomorphism and collective rationality in organizational fields. The new institutionalism in organizational analysis, p. 63-82, 7, 1991.

EISENHARDT, K. M. Building theories from case study research. Academy of Management Review, v. 14, n. 4, p. 532$550,1989$.

EISENHARDT, K. M.; GRAEBNER, M. E. Theory building from cases: Opportunities and challenges. Academy of Management Journal, 50(1), 25-32, 2007.

FISHER, G. Effectuation, causation, and bricolage: a behavioral comparison of emerging theories in entrepreneurship research. Entrepreneurship Theory and Practice, v. 36, n. 5, p. 1019-1051, 2012.

GARUD, R.; HARDY, C.; MAGUIRE, S. Institutional entrepreneurship as embedded agency: An introduction to the special issue. Organization Studies-Berlin-European Group For Organizational Studies-, v. 28, n. 7, p. 957, 2007.

GEORGE, G.; HOWARD-GRENVILLE, J.; JOSHI, A.; TIHANYI, L. Understanding and tackling societal grand challenges through management research. Academy of Management Journal, v. 59, n. 6, p. 1880-1895, 2016.

GREENWOOD, R.; SUDDABY, R. Institutional entrepreneurship in mature fields: The big five accounting firms. Academy of Management Journal, v. 49, n. 1, p. 27-48, 2006.

GREENWOOD, R.; SUDDABY, R.; HININGS, C. R. Theorizing change: The role of professional associations in the transformation of institutionalized fields. Academy of Management Journal, v. 45, n. 1, p. 58-80, 2002.

HOFFMAN, A. J. Institutional evolution and change: Environmentalism and the US chemical industry. Academy of Management Journal, v. 42, n. 4, p. 351-371, 1999.

KARAKAYA, E., HIDALGO, A.; NUUR, C. Diffusion of eco-innovations: A review. Renewable \& Sustainable Energy Reviews, 33(May), 392-399, 2014.

LAWRENCE, T. B.; HARDY, C.; PHILLIPS, N. Institutional effects of interorganizational collaboration: The emergence of proto-institutions. Academy of Management Journal, v. 45, n. 1, p. 281-290, 2002.

LEE, J.; VENKATARAMAN, S. Aspirations, market offerings, and the pursuit of entrepreneurial opportunities. Journal of Business Venturing, v. 21, n. 1, p. 107-123, 2006

MACHADO-DA-SILVA, C. L.; GUARIDO FILHO, E. R.; ROSSONI, L. Campos Organizacionais: Seis Diferentes Leituras e a Perspectiva de Estruturação (1). Revista de Administração Contemporânea, p. 159, 2006.

MAGUIRE, S.; HARDY, C.; LAWRENCE, T. B. Institutional entrepreneurship in emerging fields: HIVIAIDS treatment advocacy in Canada. Academy of Management Journal, v.47, n.5, p.657-679, 2004.

PACHECO, D. F.; DEAN, T. J.; PAYNE, D. S. Escaping the green prison: Entrepreneurship and the creation of opportunities for sustainable development. Journal of Business Venturing, v. 25, n. 5, p. 464-480, 2010.

PACHECO, D. F.; YORK, J. G.; DEAN, T. J.; SARASVATHY, S. D. The coevolution of institutional entrepreneurship: A tale of two theories. Journal of Management, v. 36, n. 4, p. 974-1010, 2010.

PARKER, S. C. Intrapreneurship or entrepreneurship? Journal of Business Venturing, v. 26, n. 1, p. 19-34, 2011.

PHILLIPS, N.; TRACEY, P. Opportunity recognition, entrepreneurial capabilities and bricolage: connecting institutional theory and entrepreneurship in strategic organization. Strategic Organization, v. 5, n. 3, p. 313, 2007.

REYMEN, I. M.; ANDRIES, P.; BERENDS, H.; MAUER, R.; STEPHAN, U; BURG, E. Understanding dynamics of strategic decision making in venture creation: a process study of effectuation and causation. Strategic Entrepreneurship Journal, $v$. 9, n. 4, p. 351-379, 2015.

SARASVATHY, S. D. Causation and effectuation: Toward a theoretical shift from economic inevitability to entrepreneurial contingency. Academy of Management Review, 26: 243-288, 2001. 
SCOTT, W. R. Institutions and organizations: Ideas, interests, and identities. Sage Publications, 2013.

SHANE, S. Prior knowledge and the discovery of entrepreneurial opportunities. Organization Science, v. 11, n. 4, p. 448469, 2000.

SHANE, S.; LOCKE, E. A.; COLLINS, C. J. Entrepreneurial motivation. Human Resource Management Review, v. $13, \mathrm{n}$. 2, p. 257-279, 2003.

SHANE, S.; VENKATARAMAN, S. The promise of entrepreneurship as a field of research. Academy of Management Review, v. 25, n. 1, p. 217-226, 2000.

SU, J.; ZHAI, Q.; KARLSSON, T. Beyond red tape and fools: Institutional theory in entrepreneurship research, $1992-2014$. Entrepreneurship Theory and Practice, 2016.

TOLBERT, P. S.; DAVID, R. J.; SINE, W. D. Studying choice and change: The intersection of institutional theory and entrepreneurship research. Organization Science, v.22, n.5, p.1332-1344, 2011.

THOMPSON, N. A.; HERRMANN, A. M.; HEKKERT, M. P. How sustainable entrepreneurs engage in institutional change: insights from biomass torrefaction in the Netherlands. Journal of Cleaner Production, v. 106, p. 608-618, 2015.

WELTER, C.; MAUER, R.; WUEBKER, R. J. Bridging behavioral models and theoretical concepts: effectuation and bricolage in the opportunity creation framework. Strategic Entrepreneurship Journal, v. 10(1), p. 5-20, 2016.

YIN, R. K. Case study research design and methods third edition. Applied social research methods series, 5, 2003. 